\section{DIGITAL COMMONS \\ @ UNIVERSITY OF SOUTH FLORIDA}

\section{ब(96R)}

Journal of

Global Education and Research

\title{
Reggio Emilia and the arts approach: Two exceptional examples of multimodal learning in early years
}

\author{
Fadumo Aden \\ University of East London, faduma06@hotmail.co.uk \\ Evgenia Theodotou \\ University of East London, e.theodotou@uel.ac.uk
}

\begin{abstract}
Follow this and additional works at: https://digitalcommons.usf.edu/jger
Part of the Art Education Commons, Curriculum and Instruction Commons, and the Early Childhood Education Commons

This Refereed Article is brought to you for free and open access by the M3 Center at the University of South Florida Sarasota-Manatee at Digital Commons @ University of South Florida. It has been accepted for inclusion in Journal of Global Education and Research by an authorized editor of Digital Commons @ University of South Florida. For more information, please contact digitalcommons@usf.edu.
\end{abstract}

\section{Recommended Citation}

Aden, F., \& Theodotou, E. (2019). Reggio Emilia and the arts approach: Two exceptional examples of multimodal learning in early years. Journal of Global Education and Research, 3(2), 158-167.

https://www.doi.org/10.5038/2577-509X.3.2.1050

Corresponding Author

Fadumo Aden, Stratford Campus, Water Ln, London E15 4LZ, United Kingdom

Revisions

Submission date: Oct. 19, 2018 ; 1st Revision: Feb. 4, 2019; 2nd Revision: May. 22, 2019; 3rd Revision: Jun. 28, 2019; 4th Revision: Aug. 24, 2019; Acceptance: Nov. 22, 2019 


\title{
Reggio Emilia and the Arts Approach: Two Exceptional Examples of Multimodal Learning in Early Years
}

\author{
Fadumo Aden ${ }^{1}$ and Evgenia Theodotou ${ }^{2}$
}

\author{
Cass School of Education and Communities \\ University of East London, UK \\ ${ }^{1}$ faduma06@hotmail.co.uk \\ e.theodotou@uel.ac.uk
}

\begin{abstract}
The Reggio Emilia approach offers children a unique experience of self-exploration embedded in the arts. This has strong links with multimodal teaching and learning. This is based on the argument that they both offer children the opportunity to communicate in multimodal ways such as drawing, drama play, gestures, music and speaking whilst placing children at the centre of their learning. This paper focuses on the concept of multimodal learning and discusses the Reggio Emilia approach and the arts approach in an effort to create links with the contents of multimodal learning. Furthermore, it compares and contrasts both approaches and identifies similarities and differences.
\end{abstract}

Keywords: multimodality, arts, learning, communication

\section{Introduction}

Multimodal learning contextualizes teaching and learning "in a world no longer bonded by a printed text only" (Miller \& McVee, 2012, p. 1). Multimodal learning can be defined as the process of learning in which the learners can use different ways of communicating and internalizing new knowledge apart from text (Mellgren \& Gustafsoon, 2011). Thus, it is prudent that classroom practices are updated in order to include learning through multimodality. Classroom practices must take into serious consideration that "humans have always drawn on more than language to share their experience of the world" (Silva \& Feez, 2018, p. 14). Multimodality is imperative in terms of developing the ways in which children "bring together different modes to make meaning" through methods such as the introduction of written text, facial expression, and gestures (Silva \& Feez, 2018, p. 14).

Multimodality is a very important factor in people's communication and influences both their professional and personal life. As a result, a strong impact can be identified in education and more specifically in the early years (0-8 years old) education. Enabling multimodal learning and communication is fundamental in the early years classroom because it allows children to communicate through the use of different forms of expressions - both verbal and nonverbal.

Reggio Emilia is an inspirational early years approach which "is not an educational model in the formal sense, with defined methods, teacher certification standards, and accreditation processes" but rather it "embraces a progressive vision of education in seeking new kinds of schools for young children" (Edwards \& Gandini, 2018, p. 365). The Reggio Emilia approach was named after a 
town in northern Italy and is focused on children from birth to 6 years old. The Reggio Emilia approach was introduced by Loris Malaguzzi during a time where Europe, specifically Italy, was recovering from the World War II. The learning community which emerged was established on a set of principles that were interlinked and reliant on each other. Ultimately, this "combination of history and fundamental principles are supported by a deep civic commitment to children" (McNally \& Slutsky, 2017, p. 1925). The Reggio Emilia approach is still immensely relevant in contemporary educational research and institutions.

The Reggio Emilia approach embraces multimodality and emphasises that children express themselves through their hundred languages (which is a metaphor for the diverse ways children express and learn) and hence, enables children to utilise their creativity. The hundred languages of children recognize that "creativity allows children to engage with their world and discover new meaning" (Boyd \& Bath, 2017, p. 194). The hundred languages of the Reggio Emilia approach give children the autonomy and freedom to communicate and express themselves and therefore provide them with the flexibility to communicate in a variety of ways. The phrase "the child has a hundred languages and a hundred more" emphasizes the breadth of resources available to children which allow them to make interpretations and gain an understanding of the world around them and their place in it (Edwards, Gandini, \& Forman, 1998, p. 3). The schools which endorse a Reggio Emilia teaching style provide children with open-ended possibilities within their classrooms. Subsequently, these creative opportunities not only expand their creative and artistic capabilities, but they also give them ample opportunities to use their hundred language.

The arts approach is similar to the Reggio Emilia approach in this context because it can be used in education through an open-ended environment. Historically, the arts have had a significant influence on children's education. However, over the last two decades, the arts have gained eminence within learning curriculums. In addition, studies and research into the arts and their role in education have taken on new formats and styles in terms of learning and teaching because of the increasing use of digital media (Winner \& Vincent-Lancrin, 2013). Much like the Reggio Emilia approach, the purpose of the arts is to enable individuals to communicate or express themselves and their ideas, thoughts or feelings through their three forms, which consist of the literacy arts, performing arts and visual arts.

Adopting both the arts and the Reggio Emilia approaches in the early years settings mean children will have a leading role in their learning. This means they are able to communicate freely and express their creativity using multimodal features. Both approaches can be linked with the philosophy of multimodal learning as they both offer opportunities for children to express their ideas and feelings in a variety of ways, both verbal and nonverbal, using different modes to communicate. In addition, both approaches emphasise the importance of allowing children to express themselves without limitation and adopt the concept of education as a journey. By closely studying both approaches, it emerges both of them embrace characteristics of multimodality, since this is an important feature for effective learning in the early years.

In addition, the Reggio Emilia and the art approach are founded in the social interactions between children, which will allow children to develop their personal and interpersonal skills and learning. These approaches focus particularly on the essential aspects which influence children's learning and development (such as environment, adults) and allocate responsibilities and roles for building the future generations through collaboration with children. 
Aden and Theodotou: Reggio Emilia and the arts approach: Two exceptional examples of multimodal learning in early years

The purpose of this paper is to discuss the Reggio Emilia and the arts approaches in an effort to create links with the content of multimodality and multimodal learning. It will also highlight the approaches' contribution to the early years classroom.

\section{Defining the Content of Multimodality}

Multimodality is defined as communicating and expressing in a variety of ways such as verbal and non-verbal rather than just written or spoken language. Thus, Yelland, Lee, O'Rourke, and Harrison (2008, p. 46) argued that multimodality is referred to as the "concept of communication that subsumes the written, the visual, the gestures and the tactile into one entity." Multimodality plays a crucial role in promoting learning and emerges through a multi-dimensional approach. Therefore, the learning environment should employ a wide range of resources or materials. For instance, a multimodal environment incorporates a variety of open-ended resources such as home corner, outdoor area, book sections, role play, costumes and puzzles in order to accommodate children's interest. This will give children the opportunity to explore their environment which is built on their interest and learning needs. In addition, multimodal environments allow children's creativity to flourish and enable them to put their different ideals into practice.

This will also facilitate modes which are a key instrument in communication. A mode is described as anything which communicates meaning. According to Kress, Jewitt, Ogborn, and Tsatsarelis (2001, p. 43) a "mode is shaped and organised in a meaning-making system" and is influenced by culture. For example, children could draw, dance, or use gestures to communicate their thoughts and ideas. It has to be acknowledged in different societies one mode could have different interpretations due to the influence of culture. For example, raising your index finger towards someone would be perceived as an insult in some countries, whereas in other countries this gesture is completely inoffensive.

\section{Reggio Emilia Approach and Multimodal Learning}

Reggio Emilia is the first approach which is to be discussed as a multimodal approach. This approach bases its philosophy on the following theorists: Vygotsky, Bruner, and Dewey. The Reggio Emilia approach can be defined as one of the exemplary models of early years learning (Moss, 2016). It focuses in supporting children under the age of six years old to "learn in community and with others" (Nutbrown \& Abbott, 2009, p. 1). One of the distinguishing features of this approach is that it views "children as competent, capable learners, central to their work" (Nutbrown \& Abbott, 2009, p. 2). Thus, it considers teachers as facilitators and learning partners alongside children. Consequently, teachers are considered to take a cooperative role in order to correspond with the strong image of the child. Scott (2001, p. 22) reveals this approach believes "children are searching for the real meaning of life" and adults should listen instead of "giving them the answers" as listening to children will give them the opportunities to "think about what the answers might be." Equally, this approach highlights the importance of children as active citizens who deserve their rights to be respected. This element of Reggio Emilia links with multimodality because one of the key features of multimodality is it acknowledges children can express their ideas through various modes of communication such as gestures, visual, or oral modes.

The Reggio Emilia approach also considers the environment as a third teacher to children and argues children are capable learners in the right environment. This approach recognises the environment as a force for learning (Strong-Wilson \& Ellis, 2007) and stresses it is essential to 
their learning experience. For instance, the Reggio Emilia classroom uses mirrors to enhance children's exploration according to their own understanding, which they use as a tool to express themselves and communicate with others in a rich and meaningful environment.

A Reggio classroom is spacious with plenty of light coming through the windows. Children have access to both outdoor and indoor activities and the resources which will stimulate children to explore their interests and creativity. This practice has strong links with the concept of multimodality. It facilitates children's different learning styles, because it offers them different opportunities to explore and develop their learning. Also, it enables children to put their different ideals into practice in an environment which is built upon children's interest and learning needs.

Learning styles can be defined as different ways of learning according to the individual's choice of preferences (Hwang, 2014). Acknowledging and identifying different learning styles in a classroom will help the teachers support students individually by using teaching methods which suit each learner. In addition, it is essential teachers incorporate a method which is tailored to the child's own preferred learning style. The child will be more motivated to learn if their own learning style is embedded into their education. It is crucial to recognise the differences in each individual child's abilities, preferences, and personality. It is argued these factors have a significant impact on each child's style of learning or their "preferred ways of thinking" (Entwistle \& Ramsden, 2015, p. 14). An overview of the sheer range of learning methods or styles highlights "the importance of qualitative differences in the approaches to, and processes of, learning" (Entwistle \& Ramsden, 2015, p. 9).

In the context of the Reggio Emilia approach, learning styles are implemented in education by allowing children to learn, do, and take part in a series of activities in the class by offering a variety of choices to the learner. Furthermore, this approach is likely to encourage children to use their initiative as they are perceived as capable learners with the freedom to learn through their own explorations (Vasudevan, 2014).

Moreover, multimodal learning is promoted to a certain extent in both the National Curriculum and the Early Years Foundational Stages (EYFS) in the UK through play or child-led and childinitiated activities. Children's learning is stimulated through activities which are beneficial and likely to "enable children to make connections with many areas of learning and experience" (Wood, 2010, p. 12). Through the integration of play and activities or tasks directed from the curriculum, teachers are required to make assessments in order to provide feedback within their own approaches to learning as well as if the educational outcomes had been met. The Reggio Emilia approach and the multimodal approach are similar to theories of constructivism which are "undoubtedly one of the most influential philosophies in education in the twenty-first century" and is highly revered in the field of early years education much like Dewey's philosophy which stemmed from the fundamental belief that children learn through doing (Krahenbuhl, 2016, p. 97). Additionally, these approaches make an argument in line with that of the pedagogical approach which is practiced in primary education.

In the Reggio Emilia approach, there is no set curriculum for children but, as an alternative, it encourages children's expression through art activities. Art is viewed as a vehicle for learning through forms such as role play, drawing, music, and movements. Each Reggio Emilia classroom has an "atelierista, the experienced and qualified artist" (Nutbrown \& Abbott, 2009, p. 2). Also, it has an atelier which is referred to as an art studio in which children can express their artistic character such as "painting, drawing, and working in clay-all the symbolic languages" (Vecchi, 
1998, p. 141). This feature of Reggio Emilia links with multimodality because they both stress the significance of promoting and broadening interpretations of learning. They also both emphasised children use their senses and different modes to express themselves. For instance, in the Reggio Emilia approach children communicate in various modes to express and understand the world around them, which is a basic element of multimodal communication.

Therefore, this approach does not set a fixed curriculum for children and instead enables children to build the foundation for their learning by allowing them to decide their learning goals without having to meet certain criteria or standards through a short and long-term project-orientated curriculum. This is documented and revisited in order to look at their progress and sustain their learning. However, this documentation is "carefully arranged and organised" along with the transcriptions of children's discussions and comments about their work as this signifies children's "thinking and learning" (Nutbrown \& Abbott, 2009, p. 52). Adopting this approach in the classroom means children would not be judged for being incapable of understanding or achieving specific goals set by teachers. Equally, this approach emphasises the importance of "respecting the perspectives to be found between different generations" such as children and adults, as it strongly advocates to "pay attention to what children say" and requires adults to "uncover what they mean" (Scott, 2001, p. 21).

Hence, the Reggio Emilia approach emphasises learning should not be based on a set curriculum, but instead it should be based on children's own interest as this will allow children to lead their learning. It has to be noted in this approach children will have an active role in their leaning and collaborate with their peers and teachers. These features of the Reggio Emilia approach are important as they link with multimodal learning. They put children in the centre of their learning and enable them to integrate a multimodal learning approach which encourages them to express their voices through different modes of their own choosing. For example, children could use different classroom resources such as paint, musical instruments, or mark-making to communicate and also use them as a learning tool. By not having a set curriculum and being able to lead their own learning journey allows children to use and implement different modes of communication and to raise their own voice. These are integral parts of a multimodal environment and thus a strong link is shown between the Reggio philosophy and the multimodal learning philosophy.

This approach juxtaposes with John Locke's theory (as cited in Berger, 1991, p. 209) which states "all knowledge is taught and therefore children are born as a blank slate". Locke further argues children need to be taught since they have no knowledge when they are born. On the other hand, the Reggio Emilia approach believes children are born with the appetite for learning and can express this in many ways through their senses. Therefore, children have the capacity to experience the world through their own creativity and imagination. Consequently, it argues children's learning should not be based on a fixed curriculum as children should be the leaders of their learning. This is also linked strongly with multimodal learning because, as discussed above, multimodal learning emphasises the significance of children's self-expression through different modes and tools in order to develop their competence.

In summary, strong links can be found between elements of the Reggio Emilia approach, which supports multimodality and multimodal learning. For example, multimodality suggests children can communicate and express their ideas according to their needs by using their available modes to create meaning such as visual, touch, smell, or taste. Hence, the multimodality and the Reggio Emilia approach share the aim of assisting children's learning by providing an open-ended environment in which the adult educators facilitate this process. Having discussed the content of 
the Reggio Emilia approach and created links with multimodal learning, the next section will introduce the arts as another approach to implement multimodality successfully in early years settings.

\section{The Arts Approach and Multimodal Learning}

The arts are another approach which is prominent in multimodal learning in the early years. The arts cannot be defined by using the conventional formats or using the pedagogical theories since they have their own communication system. Matthews (2008, p. 139) highlights the arts are freedom since "individuals choose what they want to say" and how they want to say it. In addition, he claims that the arts offer opportunities for "creativity and sociable educational experience" (p. 139).

Children in early years settings can use a variety of materials such as papers, leaves, chalks, movements, music, or role play to express themselves. The arts allow people to express themselves without limitations or set criteria. Similar to multimodality, the arts approach supports learners by offering opportunities to use the different art forms such as drawing, drama, puppetry, etc. as tools for their communication without limiting themselves to subject-based curricula or specific activities. It focuses on developing children's learning that is based on children's interests. The arts are divided into three forms, which include visual arts, literary arts and performing arts. All these forms can be considered as different modes, which are used to communicate thoughts and ideas. This is similar to multimodality as the arts are consistent with the idea communication is multidimensional and through the different forms of art, children can express their feelings and thoughts freely, which they might have found to be more challenging if they were limited to words.

Observing the arts through the pedagogical theories and philosophers, Dewey (1934, p. 254) revealed "art breaks through barriers that divide human beings, which are impermeable in ordinary association." It is important to note the main purpose of the arts is not to educate, but instead to communicate. As Theodotou (2015) explains, the arts promote self-expression and limit social barriers by allowing children to interact and communicate with one another through methods that differ from their usual modes of interaction.

However, Eisner (1998) suggests the arts have pedagogical value. For example, children can use the arts to build existing knowledge, develop their hand and eye co-ordination and fine motor skills; and, while they are interacting with their peers, they can also develop social and emotional skills. A good example to support this argument can be that the arts are one of the specific areas of the Early Year Foundation Stage (EYFS) in the UK and more specifically in the Expressive art and Design. This area of the EYFS highlights that children need to explore using media and materials and encourages creativity (Department for Education, 2018). The arts are customarily a part of children's forms of free play. They allow children to participate in their learning journey and take away existing challenges, which are placed upon children in order to meet certain distinctive milestones at specific times. This is very important particularly in the early years settings where play is encouraged as it is an essential part of a child's holistic development. Moreover, the arts allow children to develop their communication skills so that they will be able to play and communicate creatively with one another (Theodotou, 2015).

The arts approach can expand on the understanding of early years providers and promote a new teaching strategy, which can be implemented to improve children's learning. This is based on the argument that the arts have links with multimodal learning as they both strive for learning which 
Aden and Theodotou: Reggio Emilia and the arts approach: Two exceptional examples of multimodal learning in early years

is multi-layered and driven by the children's own interest. Therefore, this approach highlights there should not be restrictions as this will narrow children's learning experiences.

Having discussed the philosophy of the arts and created strong links with multimodal learning, the next section focuses on the advantages of both of the discussed approaches on children's learning in relation to multimodality. The arts and Reggio Emilia approach could provide many benefits to children's learning if implemented in the classroom in a manner, which supports multimodality such as planning and preparing around educational tasks which need to be completed across interactive and play activities.

\section{The Arts and Reggio Emilia Contribution to the Early Years Settings and Multimodality}

Both approaches have one common area in their philosophy, which is the link to multimodal learning and multimodality. More specifically, the Reggio Emilia approach highlights that children communicate through a hundred languages which is a metaphor for the diverse ways children express and learn. Similarly, the arts approach is categorised into three different forms in which children can express themselves in different ways. Comparing the above arguments, it is obvious both the Reggio Emilia and the arts approach not only provide opportunities for self-expression, but also educational development such as cognitive, social skills, creativity, collaboration, communication skills, and self-discovery. It is important to note this takes place in an environment in which children learn and communicate effectively with a plethora of different ways of communication and different modes to utilise.

The Reggio Emilia approach argues the journey of education "is not to acquire a body of knowledge but rather to question and challenge" (Smidt, 2013, p. 55). In a similar vein, the arts offer an open-ended communication to participants and thus enable them to incorporate modes of communication to voice their thinking in their own individual ways (Theodotou, 2015). This contributes to children's effective learning and has strong links with multimodality as it offers children choices to empower their individual competences. It also allows them to utilise and embrace different forms of expression based on their learning styles and interests.

Moreover, both approaches argue children need experiences based on practice in the same way as Bruner's (1996) theory, which recognised learning occurs as a result of direct experiences. Nonetheless, each approach promotes it differently. For instance, the Reggio Emilia approach believes children should "learn in community and with others" (Nutbrown \& Abbott, 2009, p. 1). By learning within their community children will be able to develop a sense of belonging and learn about the diverse culture of their community, which also means children are respected and valued by adults. This will enable them to interact with different modes of communication and adapt the ones which are closer to them.

Furthermore, the arts promote learning in a way which can be linked with theorists that adopt a socio-constructivism framework such as Bandura, Bruner, and Vygotsky. These theorists strongly argue "both children and adults co-construct their knowledge through interactions with people and their environment" (Dodd-Nufrio, 2011, p. 235). Also, as a result of the arts, children can use the unique forms of the arts to freely communicate with others through drawing, music, movement, words or writing, singing, or drama which is similar to the multimodal approach which argues children can communicate through a variety of ways. 
However, it should be noted there are arguments which are opposed to the above statements regarding the pedagogical framework in teaching and learning. These arguments are focused on Locke's (1841) statement that children are born as a blank slate. He also highlights the importance of guidelines for children by arguing children need a sense of direction. Also, adults are identified as more knowledgeable and children are presented as not being as competent as the Reggio Emilia approach argues. This contradicts the concept of multimodality, which states children are able to express themselves and expand their learning by using their hundred languages, the resources within their environment, and their own senses without limitation or the need for adult instruction.

Focusing on teaching and learning, the arts could also be criticised for not having a clear educational focus in contrast to the standard types of teaching systems (Theodotou, 2015). Nonetheless, their contribution is they offer "other forms of education that differ from the norm" and could be described as "aspirating to reinforce change into present educational system" (Edwards, 2002, p. 2).

In summary, both approaches accommodate multimodality in learning to allow early years educators to utilize these approaches and accommodate them into their teaching styles. This will allow children to have a multimodal environment which encourages their learning and creativity. The Reggio Emilia and the arts approach both strongly argue children can communicate and learn by engaging with different modes of communication and the resources of the environment without adult restrictions. Therefore, both approaches intensely emphasise children have the strength to express their thoughts, ideas, and experience using a variety of modes apart from verbal and written communication, which is the foundation of multimodality. Likewise, both approaches have pedagogical values for children and teachers as they encourage education, which is based on a balanced power and respect.

\section{Conclusions}

This paper has analysed the content of multimodality and multimodal learning with a particular focus on the early years settings. The Reggio Emilia and the arts approach were both discussed and linked with the basic features of multimodality. This paper also discussed the ways in which these approaches offer children a unique experience of self-exploration embedded in the different modes of communication using their hundred languages. It linked the approaches and explored them in the classroom practice to enhance children's learning and the significance of multimodality in communication and learning, focusing predominately on the Reggio Emilia and the arts approach and their contributions.

This paper argues the Reggio Emilia approach has strong links with multimodal learning, because they both emphasise a philosophy which is rooted in children being the centre of their learning and promotes a variety of styles and modes of learning. Similarly, strong links can also be found between the arts and multimodality as they both derive from the freedom of children's communication systems through their own expression and creativity.

This paper could be used specifically by individuals who are interested in the field of early childhood studies. It could support those who would want to further understand the link in the philosophy between the Reggio Emilia approach, the arts, and multimodal learning. Furthermore, the findings of this paper will be of interest to early years practitioners, in expanding their knowledge, understanding and practice of these approaches in the early years classroom. Equally, this paper lays the foundation for future research studies or projects in the early years settings 
Aden and Theodotou: Reggio Emilia and the arts approach: Two exceptional examples of multimodal learning in early years

about multimodality as it contributes and adds to the existing growing body of knowledge and research which indicates the importance of multimodality embedded learning in the early years education.

\section{References}

Berger, E. H. (1991). Parent involvement: Yesterday and today. The Elementary School Journal, 91(3), 209-219.

Boyd, D., \& Bath, C. (2017). Capturing student perspectives through a "Reggio" lens. International Journal of Teaching and Learning in Higher Education, 29(2), 192-200.

Bruner, J. S. (1996). The culture of education. Boston, MA: Harvard University Press.

Department for Education. (2017). Statutory framework for the early years foundation stage: Setting the standards for learning, development and care for children from birth to five. Retrieved from https://www.foundationyears.org.uk/files/2017/03/EYFS_STATUTORY_FRAMEWORK_2017.pdf

Dewey, J. (1934). Art as experience. New York, NY: Penguin.

Dodd-Nufrio, A. T. (2011). Reggio Emilia, Maria Montessori, and John Dewey: Dispelling teachers' misconceptions and understanding theoretical foundations. Early Childhood Education Journal, 39(4), 235237.

Edwards, C. P. (2002). Three approaches from Europe: Waldorf, Montessori, and Reggio Emilia. Early Childhood Research \& Practice, 4(1), 1-24.

Edwards, C. P., \& Gandini, L. (2018). The Reggio Emilia approach to early childhood education. In J. L. Roopnarine, J. E. Johnson, S. F. Quinn, \& M. M. Patte (Eds.), Handbook of international perspectives on early childhood education (pp. 365-378). London, England: Routledge.

Edwards, C., Gandini, L., \& Forman, G. (1998). The hundred languages of children. The Reggio Emilia approach: Advanced reflections. London; England: Ablex.

Eisner, E. W. (1998). Does experience in the arts boost academic achievement? Art Education, 51(1), 7-15.

Entwistle, N., \& Ramsden, P. (2015). Understanding student learning. New York, NY: Routledge.

Hwang, G. J. (2014). Definition, framework and research issues of smart learning environments-A context-aware ubiquitous learning perspective. Smart Learning Environments, 1(4), 1-14. doi:10.1186/s40561-014-0004-5

Krahenbuhl, K. S. (2016). Student-centred education and constructivism: Challenges, concerns, and clarity for teachers. The Clearing House: A Journal of Educational Strategies, Issues and Ideas, 89(3), 97-105.

Kress, G., Jewitt, C., Ogborn, J., \& Tsatsarelis, C. (2001). Multimodal teaching and learning: The rhetorics of the science classroom. London, England: Bloomsbury.

Locke, J. (1841). An essay concerning human understanding. London, England: Cheapside.

Matthews, M. (2008). How can we create the conditions for students' freedom of speech within studies in art? The International Journal of Art \& Design Education, 27(2), 133-143.

McNally, S. A., \& Slutsky, R. (2017). Key elements of the Reggio Emilia approach and how they are interconnected to create the highly regarded system of early childhood education. Early Child Development and Care, 187(12), 1925-1937.

Mellgren, E., \& Gustafsson, K. (2011). Early childhood literacy and children's multimodal expressions in preschool. In N. Pramling, \& I. Pramling-Samuelsson (Eds.), Educational encounters: Nordic studies in early childhood didactics (pp. 173-189). Dordrecht, Netherlands: Springer.

Miller, S., \& McVee, M. (Eds.). (2012). Multimodal composing in classrooms. New York, NY: Routledge.

Moss, P. (2016). Loris Malaguzzi and the schools of Regio Emilia: Provocation and hope for a renewed public education. Improving Schools, 19(2), 167-176. doi:10.1177/1365480216651521

Nutbrown, C., \& Abbott, E. (2009). Experiencing Reggio Emilia. In L. Abbott, \& C. Nutbrown (Eds.), Experiencing Reggio Emilia: Implications for pre-school provision (pp. 1-7). Philadelphia, PA: Open University Press.

Scott, W. (2001). Listening and learning. In L. Abbott, \& C. Nutbrown (Eds.), Experiencing Reggio Emilia: Implication for pre-school provision (pp. 21-29). Philadelphia, PA: Open University Press.

Silva J. H., \& Feez, S. (Eds.). (2018). Multimodality across classrooms. New York, NY: Routledge.

Smidt, S. (2013). Introducing Malaguzzi: Exploring the life and work of Reggio Emilia's founding father. London, England: Routledge.

Strong-Wilson, T., \& Ellis, J. (2007). Children and place: Reggio Emilia's environment as third teacher. Theory Into Practice, 46(1), 40-47.

Theodotou, E. (2015). The arts: An interesting approach in the early years settings. Retrieved from https://www.bera.ac.uk/blog/the-arts-an-interesting-approach-in-the-early-years-settings 
Vasudevan, L. (2014). A picture can do things words can't: Transforming representations in literacy research. In J. Flood, S. B. Heath, \& D. Lapp (Eds), Handbook of research on teaching literacy through the communicative and visual arts (Vol. 2; pp.187-194). London, England: Routledge.

Vecchi, V. (1998). The role of the atelierista. The hundred languages of children: The Reggio Emilia approachadvanced reflections. Greenwich, England. JA1 Press.

Winner, E., \& Vincent-Lancrin, S. (2013). Educational research and innovation art for art's sake? The impact of arts education: The impact of arts education. Paris, France: OECD publishing.

Wood, E. (2010). Developing integrated pedagogical approaches to play and learning. In P. Broadhead, \& J. Howard (Eds.), Play and learning in the early years: From research to practice (pp. 9-26). London, England: SAGE.

Yelland, N., Lee, L., O’Rourke, M., \& Harrison, C. (2008). Rethinking learning in Early Childhood Education. London, England: Open University Press. 